\title{
Carbohydrate deficient glycoprotein syndrome; multiple abnormalities and diagnostic delay
}

\author{
A C J Hutchesson, R G F Gray, D A Spencer, G Keir
}

\begin{abstract}
A 3 week old boy presented with abnormal thyroid function, and was treated with thyroxine. He developed multisystem disease including deafness and nephrotic syndrome, and died aged 3 months. Carbohydrate deficient glycoprotein syndrome (CDGS) was diagnosed postmortem. CDGS should be considered in all infants with apparently unrelated multiple clinical or biochemical abnormalities.

(Arch Dis Child 1995; 72: 445-446)
\end{abstract}

Keywords: carbohydrate deficient glycoprotein syndrome, thyroid stimulating hormone, sensorineural deafness.

The carbohydrate deficient glycoprotein syndromes (CDGSs) were first described in 1980, and since then over 120 patients have been recognised. ${ }^{1}$ The clinical features are age related, with developmental delay and neurological disease as prominent features in the majority of patients. However, presentation in infancy may be with a multisystem disorder. ${ }^{2} 3$ Reported clinical features include dysmorphism, skeletal dysplasia, hypoventilation, hepatomegaly, cardiomyopathy, and recurrent infections. The expression of these features can vary considerably between patients (even between siblings), and this can lead to difficulties in diagnosis. This is exacerbated by quantitative and functional abnormalities in many plasma glycoproteins, which appear to be due to defective glycosylation. ${ }^{4}$ The definitive diagnostic test, requiring only $50 \mu \mathrm{l}$ of serum, is isoelectric focusing of serum transferrin isoforms, to demonstrate a relative increase in fractions with fewer than four sialic acid residues; serum protein electrophoresis may also suggest the diagnosis. ${ }^{3}$

Children's Hospital,

Department of Clinical Chemistry

A C J Hutchesson

R G F Gray

Department of Chest Medicine

D A Spencer

Department of

Neuroimmunology,

Institute of Neurology,

London

G Keir

Correspondence to:

Dr A C J Hutchesson

Department of Clinical

Chemistry, City Hospital,

Dudley Road, Birmingham

B18 7QH.

Accepted 7 February 1995 tal hypothyroidism. He was started on thyroxine $25 \mu \mathrm{g}(7 \mu \mathrm{g} / \mathrm{kg})$ daily.

Subsequently he developed hepatomegaly and stridor due to laryngotracheomalacia. At 8 weeks of age he was noted to be dysmorphic

A boy, the second child of unrelated white parents, presented at 3 weeks of age with failure to thrive and a serum thyroid stimulating one (TSH) concentration of $13 \mathrm{mU} /$ (reference range $0 \cdot 3-3 \cdot 8)$. Serum free thyroxine was $11.7 \mathrm{pmol} / 1$ (reference range 11-24). The results of neonatal TSH screening were

\section{Case report}

with loose skin folds, inverted nipples, and dolichocephaly. Developmental delay, hypotonia, sensorineural deafness (brainstem evoked response thresholds $60 \mathrm{~dB}$ on the right and 45 $\mathrm{dB}$ on the left, with normal tympanometry), blindness, skeletal dysplasia, and a nephrotic syndrome (serum albumin concentration 22 $\mathrm{g} / \mathrm{l}$, urine protein $1377 \mathrm{mg} / \mathrm{mmol}$ of creatinine) were present. A number of other biochemical parameters were abnormal (table), suggesting a multisystem disorder and indicating conflicting diagnoses.

Despite thyroxine treatment, the plasma TSH concentration remained raised at $4 \cdot 8$ $7.6 \mathrm{mU} / \mathrm{l}$. Ultrasonography revealed an anatomically normal thyroid. Cranial computed tomography showed no abnormality to explain the visual or auditory deficits, and fundoscopy was normal. He developed left ventricular failure with a pericardial effusion, and died from respiratory failure aged 106 days. Permission for a full necropsy was denied; but a postmortem liver biopsy specimen demonstrated hepatic fibrosis, and a muscle biopsy specimen was consistent with neurogenic muscular atrophy. Analysis of transferrin isoforms in antemortem plasma demonstrated a marked increase in disialotransferrin and asialotransferrins $(40 \%$ and $20 \%$ of total transferrin respectively; normal results $<8 \%$ and $<1 \%$ ), indicating a diagnosis of CDGS type I.

\section{Discussion}

Protein abnormalities in CDGS type I can result in a wide range of apparently unrelated biochemical findings, which may lead to inappropriate lines of investigation and delay in making the correct diagnosis. This patient

Abnormal biochemical parameters in an infant with CDGS

\begin{tabular}{|c|c|c|}
\hline & $\begin{array}{l}\text { Case } \\
\text { studied }\end{array}$ & $\begin{array}{l}\text { Reference } \\
\text { range }\end{array}$ \\
\hline \multicolumn{3}{|l|}{ Plasma } \\
\hline Thyroxine (pmol/l) & $11 \cdot 7$ & $11-24$ \\
\hline TSH $(\mathrm{mU} / \mathrm{l})$ & 13 & $0 \cdot 3-3 \cdot 8$ \\
\hline Albumin $(\mathrm{g} / \mathrm{l})$ & 22 & $30-50$ \\
\hline Total protein $(g / 1)$ & 45 & $55-75$ \\
\hline Alkaline phosphatase (IU/l) & 1059 & $150-600$ \\
\hline Isoenzyme electrophoresis & Bone & \\
\hline Aspartate aminotransferase (IU/l) & 97 & $<35$ \\
\hline Alanine aminotransferase (IU//) & 86 & $<35$ \\
\hline Creatine kinase (IU/I) & 47 & $60-350$ \\
\hline Cholesterol $(\mathrm{mmol} / \mathrm{l})$ & $<1 \cdot 2$ & $2 \cdot 0-5 \cdot 5$ \\
\hline Random cortisol (nmol/l) & 100 & $140-700$ \\
\hline Arylsulphatase A (IU/l) & $2 \cdot 9$ & $<0.5$ \\
\hline Total hexosaminidase (IU/I) & 92 & $7 \cdot 8-9 \cdot 8$ \\
\hline \multicolumn{3}{|l|}{ Urine } \\
\hline Protein/creatinine ratio $(\mathrm{mg} / \mathrm{mmol})$ & 1377 & $<20$ \\
\hline Amino acids & \multicolumn{2}{|c|}{$\begin{array}{l}\text { Gross generalised } \\
\text { increase }\end{array}$} \\
\hline Organic acids & \multirow{2}{*}{\multicolumn{2}{|c|}{$\begin{array}{l}\text { Normal } \\
\text { Generalised increase }\end{array}$}} \\
\hline Glycosaminoglycans & & \\
\hline
\end{tabular}


illustrates and extends the range of abnormalities that may be present. Increases in plasma TSH concentration have not been reported elsewhere, although serum thyroxine concentration is subnormal in $75 \%$ of patients due to a reduced concentration of thyroid binding globulin. ${ }^{1}$ Increased concentrations of growth hormone and insulin in the presence of normal growth and blood glucose have been recognised and are thought to be due to impaired receptor function. ${ }^{14}$ Variable increases in prolactin and follicle stimulating hormone have also been described. ${ }^{1}$ Likewise, deafness has not been reported previously. In addition, although mild albuminuria is usual in CDGS type $\mathrm{I}^{24}$ and renal tubular microcysts may be common, ${ }^{5}$ a nephrotic syndrome is rare. ${ }^{6}$ Other abnormalities may also lead to diagnostic delay; thus abnormal liver function may suggest primary hepatic pathology, or generalised aminoaciduria Fanconi's syndrome. As in our case, inappropriate treatment may result.
Investigation for the CDGSs is relatively simple, and requires only a small amount of serum with no particular idiosyncrasies regarding specimen collection. We suggest this group of disorders should be excluded in all patients with apparently unrelated biochemical abnormalities, particularly when neurological or multisystem clinical features are present.

1 Jaeken J, Carchon H. The carbohydrate-deficient glycoprotein Jyndromes: an overview, 7 Inherited Metab Dis 1993 , 16: 813-20.

2 Jaeken J, Hagberg B, Stromme P. Clinical presentation and natural course of the carbohydrate-deficient glycoprotein syndrome. Acta Paediatr Scand 1991; 375 (suppl): 6-13

3 Clayton PT, Winchester BG, Keir G. Hypertrophic obstructive cardiomyopathy in a neonate with the carbohydratedeficient glycoprotein syndrome. $\mathcal{F}$ Inherited Metab Dis 1992; 15: 857-61.

4 Jaeken J, Carchon H, Stibler H. The carbohydrate-deficien glycoprotein syndromes: pre-Golgi and Golgi disorders? Glycobiology 1993; 3; 423-8.

5 Strom EH, Stromme P, Westvik J, Pedersen SJ. Renal cysts in the carbohydrate-deficient glycoprotein syndrome. Pediatr Nephrol 1993; 7: 253-5.

6 Van der Knaap MS, Wevers RA, van Wijk A, Jacobs C. Finnish type nephrotic syndrome: an unknown phenotype of carbohydrate deficient glycoprotein syndrome. Abstracts of the 32nd SSIEM annual symposium. Lancaster: Kluwer Af the 32nd SSIEM annual symposic 